\title{
La comunidad polaca en España. Un colectivo particular*
}

\section{Eugenia Ramírez Goicoechea}

UNED

\section{RESUMEN}

Este artículo pretende desarrollar los aspectos más significativos de la inmigración polaca en España, desde últimos de la década de los ochenta hasta la actualidad. Por medio de diversos trabajos etnográficos y consulta de documentación, informes y datos administrativos, se pretende resaltar la singularidad de un colectivo que, a pesar de tener muchas características comunes con otros inmigrantes, se distingue por su carácter europeo, por el perfil de algunos de sus componentes y su preferencia en la escala étnica de los españoles, y, por fin, por el carácter inminente de la incorporación de su país de procedencia, Polonia, a la UE. El artículo describe a este grupo de inmigrantes a partir de su cultura y trayectoria inmigratoria, su situación administrativa, redes de captación y solidaridad, características sociodemográficas, prácticas culturales y relaciones étnicas.

\footnotetext{
* Este artículo es el fruto de un trabajo etnográfico realizado en varios momentos sucesivos. El primer trabajo de campo se realizó entre 1992 y 1993, en el contexto de una investigación más general sobre inmigración en España (E. Ramírez Goicoechea, Inmigrantes en España. Vida y Experiencias, Madrid: CIS, 1996). Junto con otros europeos del Este, el grupo polaco ha sido investigado también gracias a una financiación del Ministerio de Trabajo (1993-1994) y a la Comisión Interministerial de Ciencia y Tecnología (CYCIT, SEC-93-0584, 1993-1995). Agradezco a la UNED por un permiso sabático (1995-1996) y al Ministerio de Educación y Ciencia por una ayuda de investigación (1996-1997), años que dediqué a revisar distintas cuestiones sobre migraciones y exclusión social como Visiting Scholar en el Departamento de Sociología y Ciencia Política de la Universidad de Cambridge (UK). La metodología de investigación ha sido fundamentalmente cualitativa, consistiendo en entrevistas personales en profundidad a los propios inmigrantes de ambos sexos, pero también a informantes clave y distintos mediadores sociales y personal del Consulado, grupos de discusión y observación participante. También han sido consultados distintos documentos, informes y memorias. Los polacos han sido investigados principalmente en localidades de la Comunidad de Madrid (Madrid, Alcalá de Henares, Torrejón de Ardoz, Parla, Leganés, Miraflores de la Sierra, Bustarviejo), así como en Ávila y Segovia. He tenido la posibilidad de contrastar algunos datos y opiniones con colegas polacos en Varsovia, como, por ejemplo, los doctores Malgorzata Nalewajko y Tadeusz Milkowski, de la Academia de Ciencias de Varsovia. Una ponencia sobre las estrategias de inclusión de la migración polaca en España fue presentada en el $35^{\text {th }}$ Congress of the International Institute of Sociology (2000, Krakow, Polonia). Agradezco al evaluador de este artículo para el CIS sus interesantes sugerencias, que han colaborado a mejorar la estructura y comprensión de este trabajo.
} 


\section{INTRODUCCIÓN}

La presencia de ciudadanos polacos en España data ya desde los años sesenta, pero es hacia fines de la década de los ochenta y, sobre todo, en los noventa cuando, a partir de la apertura de sus fronteras y en una tendencia cada vez más fuerte, comienzan a verse en España de una forma significativa.

Según datos oficiales de 1999, había en España 6.517 residentes polacos (Ministerio de Trabajo y Asuntos Sociales, 2000), aunque datos más recientes, después de la última regularización, señalan como 11.342 los residentes polacos en nuestro país (Ministerio del Interior, 2001). Obviamente, la cifra debe ser superior, según el Consulado de Polonia en Madrid y otros mediadores sociales.

Hasta ahora, los polacos han representado el conjunto más voluminoso de todos los procedentes de países ex socialistas, aunque están siendo seguidos muy de cerca por rumanos, búlgaros y ucranianos. Comparten con otros ciudadanos de países europeos ex comunistas haber estado bajo el dominio de una potencia mundial como fue la ex URSS, aunque obviamente esta experiencia ha tenido sus especificidades propias. También, una imaginería respecto de Occidente elaborada a partir de determinados presupuestos y estereotipos sobre el capitalismo, la sociedad de consumo, la democracia, la libertad individual, etc. El origen europeo de todos ellos representa una singularidad frente a otros orígenes inmigrantes presentes en nuestro país como marroquíes, latinoamericanos, subsaharianos y asiáticos. Por ese y otros motivos que iremos detallando, estos inmigrantes no son percibidos como problema por parte de la opinión pública española, pudiendo establecer estrategias de inclusión social más eficaces. Junto con otros países ex socialistas, como la República Checa, Hungría, Eslovenia, en el primer grupo de la ampliación de la UE. Si sigue una evolución parecida a la de otros países mediterráneos, es incluso posible que, dentro de unos años, Polonia, frontera exterior de Europa, se convierta en país de inmigración, que de tránsito ya lo es.

\section{HACIA ESPAÑA}

\subsection{Antecedentes migratorios}

Para Polonia, la emigración ha sido un fenómeno estructural de la sociedad y la economía. Puede decirse que uno de cada tres polacos ha nacido en el seno de la diáspora migrante. La pobreza endémica de algunas regiones, junto con las consecuencias devastadoras de las guerras europeas, han sido las causas principales de emigración exterior e interior. Es- 
tados Unidos y Canadá han sido destinos principales a lo largo del siglo en sucesivas oleadas (1905, 1907, 1910) (Thomas y Znaniecki, 1918-1920). Estados Unidos ha sido un referente histórico para las culturas migratorias de este país y otros europeos, contando con fuertes comunidades inmigrantes de este origen, tal y como la sociología americana de la Escuela de Chicago ha recogido. Como nos decía un informante polaco, «... en todo el mundo se habla más de Estados Unidos... y eso deja marcado dentro, sí ir, no ir, vamos allá. $Y$ hay muchos emigrantes y siempre hay trabajo...». Australia y Nueva Zelanda también acogieron buen número de polacos.

La crisis industrial de 1978-1983 (Gorzelak, 1992), el balance negativo de la economía nacional y el desmantelamiento de una economía planificada que daba trabajo a casi todos dispararon la tasa de desempleo, impidiendo el acceso de las nuevas generaciones al sector productivo. La negativa evolución de los salarios (Fodor, 1997; SOPEMI, 1994; Gora, 1991) y de la inflación disparó la emigración. También, la dificultad de obtener una vivienda. Por ejemplo, el número de viviendas en 1988 era igual que en 1970. Para el 43\% de la población, la densidad de personas por habitación era superior a dos (Okolski, 1991). Esta situación económica se ha mantenido a grandes rasgos durante el primer quinquenio de los noventa (Lorca et al., 1997).

En el campo las cosas no han ido mejor. El colectivismo fracasó en Polonia (Gorzelak, 1992), donde las cuatro quintas partes del territorio estaban en manos de pequeños propietarios rurales (Hann, 1985). Pero también la modernización y la aplicación eficaz de la tecnología a este sector. El sobreempleo en este sector es algo que Polonia ha compartido con otros países de Europa central y oriental (Okolski, 1991). En algunas zonas más deprimidas, buena parte de las economías domésticas han sido mixtas, trabajando parte de la familia en la tierra, otra en las industrias adyacentes y buena parte emigrando. Una de nuestras informantes, trabajadora de la limpieza en Madrid, nos contaba que cuando iba de vacaciones no descansaba: tenía que ayudar en las tareas agrícolas y ganaderas de la casa de sus padres.

La liberalización de las autorizaciones para salir del país por medio de la extensión de pasaportes colaboró, sin duda, en la agilización de los movimientos de población, una corriente demográfica ya anticipada por distintos expertos (King, 1993; Öberg y Boubnova, 1993; Shetsova, 1992; Okolski, 1994).

Alemania — su desarrollo económico, su nivel de vida - ha sido, después de EE.UU., el destino europeo preferido. Polonia siempre ha mantenido difíciles y desiguales relaciones políticas y militares con la antigua Prusia y la después Alemania. Los trasvases de población y el cambio de límites fronterizos han sido constantes. Tras la caída del régimen comu- 
nista de la ex República Democrática Alemana, los polacos no tuvieron grandes dificultades para entrar clandestinamente en el país. A Alemania han emigrado también aquellos que se identificaban como alemanes «étnicos» que quedaron en la región de Silesia (Lorca et al., 1997) o aquellos que pudieron esgrimir ser descendientes de matrimonios mixtos polaco/alemán (Gorzelak, 1992). Otros destinos han sido países como Francia, Italia, Inglaterra, Holanda.

\section{I.2. La emigración a España}

Los primeros grupos en llegar a nuestro país fueron principalmente de ámbito urbano y sus alrededores: Lodz, Cracovia, Varsorvia, Wroclaw, Postdam, Lublin, Lubin, etc. Una de las zonas más castigadas, de donde proceden muchos de los que nos visitan actualmente, es Galitzja (Malopolskie, Podkarpackie, Tarnów, Rzeszów), región agrícola del sureste de PoIonia donde la industria militar y de fundiciones que proveía a la antigua URSS está en quiebra a partir de la disolución del bloque soviético. Según un informante, «allí, siempre en historia una zona muy pobre». Ante estas circunstancias «es mejor marchar, aunque sea a limpiar», nos decía una joven madre de familia polaca.

Independientemente de la llegada de algunos a partir de la instauración del comunismo, caracterizados por cierto elitismo aristocrático y militar, podemos establecer tres períodos básicos de esta inmigración a nuestro país (Arnal, 1998; Ramírez Goicoechea, 1996a).

Una fase primera entre 1980 y 1989, vinculada especialmente a la prolongada transición política polaca, con cierta liberalización de las salidas y la concesión de pasaporte, y que se clausura con la caída del Muro de Berlín y las primeras elecciones semidemocráticas. Esta emigración se caracteriza por su formación y cualificación profesional, por su edad algo más madura que las posteriores oleadas, por la fuerte presencia masculina, por la experiencia en otros países europeos como Alemania o Francia, por la consideración de España como lugar de paso a EE.UU. o Canadá, y por su concentración en zonas como Madrid, Ávila y Segovia. La estrategia principal de entrada era la solicitud de asilo y refugio, en el sentido de servir como opción temporal para alargar la posibilidad de estancia en el país; mientras tanto, buscar trabajo y, sobre todo, acceder a beneficios sociales y sanitarios de distinto tipo mientras se tramitaba la solicitud. También podían entrar con visado de turista o de tránsito por Alemania, obteniendo así en el pasaporte un sello de entrada a los países del Tratado de Shengen. Con ello no tenían problemas en desplazarse hasta España, cruzando las distintas fronteras del camino. A menudo llegaban sin ningún tipo de relación o vínculo, a pesar de que inmediatamente ponían en marcha recursos y destrezas personales de contacto con instituciones y centros de acogida. 
La segunda etapa corresponde al primer quinquenio de los noventa. Coincide con los severos ajustes económicos en Polonia y el desmantelamiento de la industria pesada y militar, el cierre de países como Canadá y EE.UU., la supresión de visado con Polonia y el descenso de edad en los grupos de salida. La desestimación de la vía del asilo y refugio como entrada es también característica de esta época. A partir de los años noventa se denegó prácticamente cualquier concesión a solicitudes provenientes del colectivo polaco, lo que no implicó la vuelta de los mismos, sino su ingreso en el grupo de inmigrantes irregulares. Del 46,2\% que representaban las solicitudes de estos nacionales en 1988, pasaron al 37,9\% en 1990, el 11,9 en 1991 y el 4,8\% en 1993 (fuente: Anuario Estadístico de Extranjería 1994) (cf. Aguilera et al., 1994). Los asentamientos se diversifican: Madrid, Valencia, Guipúzcoa y Vizcaya, Barcelona, Asturias, Guadalajara. Este momento supone un giro en las características de esta inmigración: se ha ido constituyendo una pequeña colonia que funciona como retículo de captación y ayuda en tierra española. España va configurándose como un destino interesante en el imaginario migrante (Ramírez Goicoechea, 1996b; 2000b).

La tercera se podría situar a partir de 1995, incrementándose la llegada de migrantes del sureste de Polonia, iniciándose la del noroeste y, a la vez, produciéndose la reagrupación familiar de los migrantes de principios de la década, combinándose, por tanto, la llegada de jóvenes sin experiencia profesional previa y la de elementos (maridos, mujeres, madres, padres) con más edad. En estos años observamos la consolidación de los establecimientos primeros (p. ej., el Corredor del Henares; cf. infra), pero también la diseminación del colectivo en pueblos de la Comunidad Autónoma de Madrid, en relación a los casos de compra de vivienda. Nos encontramos ya con segunda generación, la mayoría en edad escolar (18,6\% de inmigrantes residentes en la CAM con hijos; fuente: Padrón de la Comunidad de Madrid 1999), escolarizada y participando de la vida colectiva de la localidad, constituyendo, ahora mismo, una comunidad bien asentada y estabilizada, con un cierto grado de movilidad social en términos de empleo y de residencia. Algunos ya se han convertido en trabajadores por cuenta propia o ya han accedido a un piso en propiedad. Los polacos que van llegando ahora procedentes de zonas tradicionales de migración lo hacen al amparo de una red consolidada de parientes y amigos, quienes les ofrecen alojamiento y contactos para encontrar trabajo, lo que obtienen en poco tiempo. Un ejemplo paradigmático es el de Alcalá de Henares, en Madrid, donde la situación del colectivo es muy estable actualmente, tanto en términos de integración laboral y económica como social. Según varios mediadores sociales, esto se debe también a que ya ha pasado la fase en que los pisos estaban saturados por un gran número de residentes, quienes, además, gustaban de celebrar fiestas y conmemoraciones, en donde no faltaba el alcohol, siendo esto un motivo para «broncas y follones continuos», según cuentan algunos informantes españoles. «Antes, siempre aparecer en los periódicos, algún lío con polacos, por beber y 
todo eso", nos contaba una inmigrante polaca con diez años de residencia en España. Ahora, con una ocupación más razonable de las viviendas y una vida más normalizada, y a pesar de incidentes aislados, son en general bien aceptados por la población y el vecindario.

En conjunto, y para el momento actual, parece que esta comunidad no ofrece los índices de llegada que hemos podido observar para los noventa. En el contexto general del este y centro de Europa están siendo sustituidos, de alguna manera, por nuevos contingentes procedentes de otras áreas como Rumanía, Ucrania, Moldavia.

Los primeros polacos que llegaron lo hicieron en coche o en furgoneta, intentando una $u$ otra frontera, a veces pasando andando y luego haciendo autoestop. La vía de transporte más habitual actualmente es la de los autobuses, microbuses o furgonetas de rutas organizadas y preestablecidas por compatriotas, que también funcionan para volver de vacaciones, Navidad, etc., siendo el trasiego de recados, productos, prensa y dinero constante. Lugares de recogida, recorrido y llegada están bastante estipulados, así como el precio del billete, que oscila (año 2002) entre 25 y 30.000 pesetas. Otros, ya con coche, se animan a utilizarlo compartiéndolo con otros pasajeros de su misma nacionalidad y destino. Ucranianos de la región vecina de Lzov están llegando por medio de las rutas polacas. El avión es más raro, por su elevado precio. Como de costumbre, el viaje se costea con los ahorros familiares o la venta de inmuebles, tierras o enseres. Algunos, mediante pequeños negocios o con los beneficios que obtuvieron comerciando en el mercado negro.

En cuanto a su situación administrativa, los migrantes polacos más antiguos y que llevan ya en España hasta diez años tienen casi todos su situación regularizada. Los que han llegado hace menos tiempo han tenido que acreditar su estancia antes de la fecha límite de las últimas regularizaciones (1991, 1996, 2000). En la última (2000), de 4.622 solicitudes se habían regularizado 3.644 por el momento (Dirección General de la Policía, febrero 2001; datos finales todavía no publicados hasta la fecha -abril 2002-). Algunos han tenido problemas con los sellos de salida y entrada desde Alemania, con ocasión de las vacaciones anuales que suelen disfrutar. La existencia fortuita de alguna de estas marcas ha podido perjudicar la justificación de su estancia en España antes de la fecha estipulada. Por otra parte, los municipios han llevado a cabo una campaña intensa entre los inmigrantes para que se empadronen, de forma de garantizar cierta situación administrativa y civil en el municipio. Esto explica la «afloración» de inmigrantes, no sólo centroeuropeos, que está ocurriendo en nuestro país, que antes apareció registralmente invisible. Una de las pegas para regularizarse puede ser el seguir deseando trabajar en la economía sumergida para no cotizar doblemente a la Seguridad Social, aquí y en Polonia, a la espera del posible convenio que los gobiernos de ambos países establezcan para la entrada regular de inmi- 
grantes cualificados. Los casos de expulsión son raros y ellos se saben «mejor tratados» por la Policía que otros grupos (cf. infra).

\section{I.3. Redes y organización de la colectividad}

Las redes intraétnicas funcionan como para otros colectivos inmigrantes. Son decisivas para la autoorganización del colectivo porque proporcionan alojamiento, contactos para encontrar trabajo, manutención temporal, apoyo afectivo, información básica. Se construyen a partir de diferentes tipos de relación: familiares, vecinales, de paisanaje, de amistad.

Los polacos han construido originariamente su red en torno a las relaciones de parentesco, pero también de amistad. Si tenemos en cuenta que buena parte de estos inmigrantes son jóvenes, no es de extrañar que las relaciones de amistad sean potencialmente muy activas: «Ella, mi amiga, vino primero, a estar con su novio. Yo me fui con ellos...»; «Hablar con amigos y decir "vamos a ver qué pasa"». Novias siguiendo a novios, jóvenes esposas o jóvenes maridos siguiendo al cónyuge, hermanos siguiendo a hermanos, también es muy común. Hemos encontrado algunos casos de padres o madres ya mayores que han venido a visitar a los hijos, o a ayudarles ante un nuevo nacimiento, y a lo mejor se quedan una temporada y aprovechan para hacer algún trabajo. Lo que se percibe en algunos sectores es la llegada cada vez más joven de hermanos y hermanas, que vienen al amparo de los mayores, ya establecidos.

El estatus social de las mujeres en la sociedad polaca y su grado de libertad y poder de decisión explican en buena parte su importancia tanto como inmigrantes como agentes de reclamo de otros familiares y amigos. No son pocos los casos en los que ha sido la mujer (novia, amiga, esposa, madre de familia) la primera en llegar y la principal responsable del mantenimiento de la familia en el país de origen hasta que otros elementos han ido llegando y trabajando a partir de su propia experiencia migratoria.

Con independencia de algunos casos actuales procedentes de nuevas áreas de emigración a España, la red inmigrante ahora, después de un período inicial de asentamiento y estructuración, se muestra muy consolidada y densa. Ahora vienen «sobre seguro», como nos decía un mediador social, lejos de aquellas situaciones más penosas de los primeros en llegar.

El acceso de los polacos a la red asistencial de acogida a inmigrantes es ya muy puntual, en la medida en que la cobertura de grupo es altamente eficaz y vienen en unas condiciones bastante resueltas. Los primeros en llegar solicitaban asilo y refugio o acudían a Cruz 
Roja, mostrando una elevada cultura asistencial. La profundidad temporal de esta inmigración está permitiendo la incorporación de compatriotas en algunos servicios asistenciales y de acogida, así como la directa implicación de algunos de ellos en programas de alfabetización en español o incluso de formación en cultura y lengua polacas para la segunda generación. En la Comunidad de Madrid se cuenta ya con al menos tres programas de educación en polaco que, al amparo de algunos centros escolares públicos y del Consulado, aprovechan los fines de semana para dar sus clases de lengua, geografía e historia a los niños de este origen. Las clases de alfabetización suelen organizarse en torno a algunos centros de culto, como es el de Ntra. Sra. de La Paz en Madrid o Cáritas Diocesana en Alcalá de Henares.

La Iglesia y la práctica religiosa han funcionado como aglutinantes del colectivo (Ramírez Goicoechea, 1996b; Arnal Sarasa, 1998), en correlación con la tradicional vinculación Iglesia-identidad nacional en la historia de Polonia. Hay también varias asociaciones culturales en Madrid. Fórum o Asociación de Amistad Polaco/Española, ligada ahora a la Embajada de Polonia, comenzó a funcionar a partir de un núcleo de exilados y de polacos contratados en España a primeros de los años ochenta. Águila Blanca, fundada en 1993, se vincula a la llegada de los inmigrantes a fines de los ochenta y principios de los noventa. Se organizan distintas actividades culturales y se celebran las fiestas y conmemoraciones religiosas y nacionales. No tiene sede fija, pero se vincula a un núcleo de personas ligadas a la actividad social de Cáritas en Alcalá de Henares (Madrid). Editan un boletín, Archipiélago, para divulgar la asociación y sus actividades. En Bilbao se ha formado recientemente una Asociación Cultural Vasco-Polaca, vinculada a músicos polacos que fueron contratados para distintas orquestas en el País Vasco.

Las relaciones con la Embajada y el Consulado suelen ser puntuales e instrumentales, con la confianza de ser bien atendidos por sus representantes. Esto contrasta con otros centroeuropeos, como rumanos, búlgaros o rusos, quienes apenas tienen relación, reticentes todavía de posibles controles políticos. Una mediadora polaca nos decía que «polacos poder salir fuera, no había chivatos, más abierta [la sociedad polaca]. Los rumanos no, ellos tener miedo». Esto ha sido confirmado a través de nuestras distintas experiencias de campo con rumanos y búlgaros (Ramírez Goicoechea, 1996; 2000).

Según un informante, la trayectoria de la comunidad ha sido la siguiente: «Primero separarse [«buscarse la vida»], ganar dinero. Luego legalización. Ahora vida normalizada, hijos, casa propia, vida normal». Esta secuencia estaba en la base de una nueva actitud de organización y contacto para recuperar y mantener la identidad de origen por medio de las distintas asociaciones y centros culturales polacos: «Ahora ya la gente busca contacto, asociación». Tanto es así que incluso tuvimos noticia de la voluntad de constituir una ONG de 
ayuda al Tercer Mundo, con patrocinio y voluntariado a partir de la comunidad inmigrante polaca. Ahora ya no son ellos los que necesitan ayuda.

\section{CARACTERÍSTICAS SOCIODEMOGRÁFICAS}

\section{II.1. Edad y sexo}

La comunidad polaca es un colectivo en general joven (dos tercios de los residentes en la Comunidad Autónoma de Madrid son adultos jóvenes; fuente: Padrón de la CAM 1999). La mayoría de estos inmigrantes están en edad laboral, concentrándose entre las edades de 25 y 45 años, principalmente. A fines de los ochenta encontramos un buen número de adultos maduros casados, con experiencia laboral, que dejan familia —cónyuge e hijosen Polonia, produciéndose, con el tiempo, la reagrupación familiar. En un principio la edad de llegada era algo mayor que ahora. Aunque todavía llegan algunos padres y madres de hijos ya residentes en el país con objeto de trabajar, bien para ayudarles o bien para mejorar su situación en Polonia, lo cierto es que parece que la edad de los que vienen ha decrecido algo: aquellos que terminan estudios secundarios y no consideran que merezca la pena seguir estudiando en Polonia, ante la perspectiva de no encontrar empleo, o bien que, una vez terminados, no encuentran trabajo.

La fuerte presencia femenina entre el grupo polaco es un hecho. Si bien en sus inicios contamos con una mayor presencia masculina, se ha observado cierta feminización del colectivo en cuanto a que los porcentajes estimados de hombres y mujeres empleados en nuestro país son ahora prácticamente iguales, por lo menos en términos de permisos de trabajo (Ministerio de Trabajo y Asuntos sociales, 1999; Comisión Interministerial de Extranjería, 1999). Esto puede, no obstante, deberse en parte a la «afloración» de las mujeres en los distintos procesos de regularización. Una de las razones también es la mayor incidencia de desempleo femenino a partir de 1990 en relación a ciertas políticas de empleo discriminatorias por género (Fodor, 1997). Otra es el grado de independencia de la mujer, sobre todo de ámbito urbano, a quien se le reconoce un estatus de responsabilidad económica ante la familia y ante su propio futuro. Entre todos los inmigrantes del este y centro de Europa, el colectivo polaco es el que más casos de segunda generación presenta. La escolarización es general en todos ellos. Se da un caso curioso de progresiva aproximación entre las cohortes de los niños ya más mayores, escolarizados en Secundaria, y nuevos elementos inmigrantes que ingresan cada vez más jóvenes, de 16-18 años, al amparo de hermanos más mayores ya establecidos en España. 


\section{II.2. Formación y experiencia laboral}

Siendo que la educación ha sido una de las prioridades de los sistemas socialistas, la mayoría de estos inmigrantes tienen un nivel cultural relativamente alto y una cualificación profesional media. Por ejemplo, el 79\% de los empleados en construcción en 1997 tenían estudios secundarios, superando con creces el nivel educativo de los marroquíes que trabajaban en este sector, e incluso el de los españoles (Colectivo IOE, 1998). Muchos de ellos han realizado carreras técnicas medias: técnicos electrónicos, técnicos soldadores, mecánicos, ingenieros, funcionarios, docentes, enfermeras. Entre los de mayor edad podemos encontrar licenciados y titulados superiores, algunos con experiencia en puestos de responsabilidad en la administración, en la industria, en la educación, y que han decidido emigrar y devaluarse profesionalmente a cambio de un sueldo mayor y más garantizado.

No obstante, puede distinguirse entre aquellos que llegaron a fines de los ochenta y principios de los noventa y los que han ido llegando a partir de 1995 hasta ahora. Entre estos últimos, la mayoría son jóvenes que no han accedido todavía a ningún empleo en su país, a pesar de tener estudios medios, que a lo mejor han abandonado para venirse a España. Con todo, éstos han sufrido el relativo deterioro y desinversión que su país ha realizado en educación durante la decada de los ochenta, estando peor dotados que la generación de sus padres a este respecto, quienes se formaron técnicamente al amparo de la colaboración entre el sistema educativo y el mundo de la producción. No olvidemos que un grupo numeroso proviene de Galitza, una región rural de economía mixta industrial pesada y agropecuaria donde el índice de paro es muy elevado y el acceso al primer empleo prácticamente inexistente.

\section{II.3. Competencia lingüística}

Los polacos en España suelen tener algunos conocimientos de inglés, ruso o alemán, sobre todo entre aquellos de origen urbano o de zonas limítrofes con estos dos últimos países o por haber cursado alguno de estos idiomas en la escuela. El interés por aprender la lengua es frecuente, observándose un alto nivel de autodidactismo. El uso de pequeñas guías, libros y diccionarios de bolsillo es común, y el estudio en el suburbano o en los autobuses durante los trayectos de ida y vuelta del trabajo, también. La asistencia a clases y programas de alfabetización en español también se da, en torno a centros de acogida o de culto, aunque siempre dependiendo del tiempo disponible. La comunidad ya cuenta con profesorado polaco que enseña español, lo que todavía no ocurre para otros grupos. Horarios de trabajo o la distancia a estos lugares también explican en parte la elección de métodos más personalizados para aprender la lengua. En cualquier caso, saber español es una 
inversión que consideran merece la pena en términos no sólo culturales, sino de promoción laboral e integración en el país.

\section{II.4. Residencia}

El acceso a un alojamiento digno es una meta de todos los inmigrantes. La situación residencial de los centroeuropeos y europeos del Este es, en general, sensiblemente mejor a la de otros colectivos como marroquíes o subsaharianos. También es el caso de los polacos. Muchos recuerdan sus difíciles comienzos como recién llegados, cuando no había una red preexistente de acogida, acudiendo en un primer momento a algún centro de acogida. El siguiente paso ha sido compartir vivienda con otros compatriotas. Se accede a una habitación, a veces compartida, cuando hay un hueco, cuando el anterior residente ha decidido cambiar de domicilio o localidad. La selección se va haciendo por lazos de parentesco o de amistad. Escisiones y agrupamientos, al hilo de la convivencia cotidiana y sus dificultades, marcan la vida residencial de estos inmigrantes. La cohabitación de un número demasiado elevado en un mismo piso, con el consiguiente ruido y ritmo de subidas y bajadas, han provocado casos de quejas y malestar entre el vecindario. Ésta era la situación de muchos polacos hace unos años, como hemos mencionado.

El acceso a la vivienda de alquiler no ha sido demasiado difícil para estos grupos, en cuanto que la población local desconfía menos de ellos que de otros grupos, no mostrando especial aversión a ser sus vecinos (Díez Nicolás, 1999: 36), y además han podido acceder a promociones del Ayuntamiento y otros organismos a precios razonables, lo que ha sido fundamental para la normalización residencial de estos grupos. También gracias a empleos más estables, que permiten compartir menos los gastos y pagar más por donde uno vive y duerme. Ahora, con una antigüedad en algunos de entre ocho y diez años, con trabajo estable los dos miembros del matrimonio y con una perspectiva de futuro a medio y largo plazo, comienzan a darse casos de adquisición de pisos en propiedad, generalmente en zonas acordes con su nivel adquisitivo. La reunificación familiar o el nacimiento de hijos también promueven este tipo de selección residencial cada vez más autónoma e independiente.

El grupo de origen polaco está presente en casi todas las Comunidades Autónomas, pero el $58 \%$ del colectivo se concentra en la Comunidad de Madrid (Ministerio de Trabajo y Asuntos Sociales, 1997; 1999), sobre todo en el Corredor del Henares (Alcalá, Torrejón, Coslada), en el suroeste (Leganés, Parla, Móstoles, Getafe, Alcorcón, Fuenlabrada, Pinto) o en barrios madrileños como Carabanchel y Aluche. Ahora se está produciendo una mayor dispersión en relación a la movilidad residencial del colectivo, que ya va accediendo 
a pisos en propiedad y, obviamente, busca zonas a su alcance. Multitud de pueblos de Madrid están acogiendo a estos nacionales: El Molar, Valdemoro, Collado Villalba (Lora Tamayo, 1999), Villanueva del Pardillo, Miraflores, Guadalix. En Toledo, Ávila, Segovia, Barcelona, Valencia, Guadalajara, Santiago de Compostela, Córdoba, Logroño y otros municipios han constituido también asentamientos estables. Tres factores explican estas ubicaciones: el precio de la vivienda (tanto en alquiler como en propiedad), la preexistencia de compatriotas y la proximidad de áreas urbanas en donde se les demanda como fuerza de trabajo. Como trabajadores temporales acogidos a las cuotas de inmigración, se les comienza a ver como residentes temporales en los campos agrícolas de algunas provincias andaluzas.

\section{II.5. Inserción laboral}

Como ocurre con inmigrantes de otros orígenes nacionales, la mayoría de estos trabajadores se emplean en sectores distintos e inferiores en términos de su perfil y capacitación profesional. $Y$ hay bastante coincidencia para todas estas nacionalidades. Su inserción laboral se ha realizado en el contexto de una estructura económica española caracterizada por la precariedad del empleo y por la oferta en determinados sectores.

Se han dedicado, hasta ahora, principalmente a la construcción, hostelería y servicio doméstico: «era lo único que daban cupos», nos dice un mediador polaco. Han sido estos sectores los que más demanda de trabajadores han provocado en la actual estructura económica de nuestro país. «Ahora nueva ley permite otras profesiones», nos vuelve a decir, lo que tiene que ver con ciertas expectativas de movilidad social que comentamos dentro de unas líneas. El porcentaje de polacos empleados en la construcción para 1997 era del $41,4 \%$ (Colectivo IOE, 1998). Se suelen organizar cuadrillas generalmente por lugar de origen, si bien los ucranianos comparten esferas de trabajo con los polacos, a los que pueden estar vinculados lingüística y culturalmente. Se les contrata para reformas de albañilería, mantenimiento, instalaciones, fontanería, etc., tareas a las que estaban acostumbrados en sus países de origen por pura necesidad de hacerse uno mismo las reparaciones domésticas o a amigos o familiares: «Siempre arreglábamos en nuestro país, no se puede pagar para reparar», nos decía un informante polaco. Trabajan para pequeños empresarios españoles constructores de chalés, que contratan operarios por obra, muchas veces sin Seguridad Social. No es infrecuente que el empleador sea incluso un propio connacional que, de este modo, organiza un grupo de trabajo. No siempre las relaciones laborales son justas en este último caso, indicándonos que la insolidaridad y el ánimo de lucro es a menudo independiente de las coincidencias étnicas. Envidia y competencia por los trabajos también se dan (Arnal Sarasa, 1999). 
Otras actividades frecuentes son las de jardinero, chófer, conductores, dependientes esporádicos, encargados o vigilantes en fincas, reparadores de diversa índole, repartidores, descargadores de mercancías. Algunos se dedican a traer productos polacos, que se venden y compran en lugares próximos a la llegada de las furgonetas de transporte entre PoIonia y España, o se distribuyen por la red de conocidos y amigos que encargan lo que necesitan. En España antes era raro encontrarlos en la agricultura, como temporeros, labores que sí han sido más frecuentes en otros países, como en la vendimia francesa o en la floricultura holandesa (sólo el 4\% trabajaba en el agro en 1997; Colectivo IOE, 1998). Sin embargo, este año (2002) mujeres polacas han sido contratadas temporalmente para la recogida de la fresa en Huelva, como contingente migratorio pactado entre el gobierno español y el polaco. Este año han sustituido a los marroquíes para esta tarea, empleados hasta ahora para estos menesteres.

Las mujeres trabajan, casi siempre, en el servicio doméstico, principalmente como externas, a sueldo o por horas. Puede que su primer trabajo haya sido como internas (residiendo en la propia casa), pero cambian rápidamente al trabajo externo en cuanto consiguen alojamiento fijo o trabajo por horas con un nivel retributivo suficiente. Después de dominicanas y filipinas, las polacas son las que se emplean más en servicio doméstico, con un $59,9 \%$ del colectivo de compatriotas (Instituto Universitario de Nuevas Tecnologías, 1995). De hecho, es para este sector de actividad para el que se concedieron más permisos de trabajo en el contingente de 1999 (Ministerio de Trabajo y Asuntos Sociales, 2001). También se las encuentra como camareras y cocineras en diversos establecimientos de hostelería.

Los polacos muestran una incipiente movilidad social en términos de autoempleo (Morokvasik, 1991). Por una parte, muchos empiezan como ayudantes y son rápidamente promocionados a albañiles, en función de un imaginario que les otorga mejores credenciales que a otros (cf. infra). Por otra, no son pocos los que se establecen por su cuenta, como autónomos, aglutinando una cuadrilla de trabajadores de su propia nacionalidad. La compra o alquiler de una furgoneta, materiales, herramientas, algún local, son las inversiones a corto plazo para una promoción a medio y largo. Muchas mujeres también quieren tener su propia empresa y salir de la limpieza. Algunas querrían montar un bar, una pastelería, una tienda de embutidos. Piensan que la gastronomía polaca podría tener éxito en España. Y se animan a partir de cierta estabilidad económica familiar, al hilo de que sus maridos ya tienen un trabajo y unos ingresos estables. Piensan en otras familiares o amigas como socias. Indicios de esta voluntad y perspectiva de mejora lo constituyen la confección de currículas para enviar a distintas empresas, retomando capacidades y perfiles profesionales que pudieran tener antes de emigrar a España o bien imaginándose en otras tareas que no sean las de limpieza. No obstante, todavía está por verse la materialización de estos proyectos. 
Como hemos dicho más arriba, los empleos se consiguen mediante la red de compatriotas, bolsas de empleo de las ONGs, revistas como Segunda Mano, o bien en lugares de contratación informal como algunas plazas o calles donde se reúnen a la espera de la demanda de los empleadores.

Según información del Consulado polaco en Madrid, existen conversaciones bilaterales entre ambos países para la importación de mano de obra cualificada, sobre todo técnicos informáticos, aunque no exclusivamente, tal como es el caso de las recolectoras de fresa muestra. Estos convenios permitirían el reconocimiento del trabajo realizado en cualquiera de los dos países a la hora de la cotización a la Seguridad Social y el derecho al disfrute de la correspondiente pensión de jubilación.

\section{PRÁCTICAS CULTURALES Y MANTENIMIENTO DE LA IDENTIDAD}

Desde la perspectiva antropológica que sostiene este trabajo, se analizan a continuación aquellas prácticas culturales que el trabajo de campo ha detectado como fundamentales para el mantenimiento de la identidad grupal. En general, el colectivo polaco muestra recursos grupales bastante eficaces para el mantenimiento de su identidad, relacionados muy directamente con la reproducción familiar y doméstica y con el ámbito de las creencias religiosas. A través de las dinámicas y prácticas en estos ámbitos, la comunidad refuerza su sentido de pertenencia sin exclusión de otros ámbitos de referencia más globales. Como los estudios recientes de globalización nos muestran, estos fenómenos no están reñidos con un proceso de relocalización y redefinición continua de la identidad sin pérdida de referencia grupal (Appadurai, 2000; Friedman, 1994).

\section{III.1. Parentesco y familia. Segunda generación}

En consonancia con su ideología católica, el polaco tiene en alta estima los valores familiares, orientando su conducta en gran medida hacia esta institución. La mayoría de las uniones están sancionadas matrimonialmente por la Iglesia. No son pocos los que se han casado en España con otros inmigrantes como ellos, aunque hemos contactado también con algunos matrimonios mixtos. La boda, católica, en la iglesia del barrio, reúne a familiares y amigos, con la consiguiente celebración posterior. El sueño del viaje de novios a Canarias o Mallorca no suele cumplirse, debido principalmente a razones laborales y económicas.

Consideran la edad de matrimonio muy tardía en España, comparada con la habitual en Polonia. Del mismo modo, el período de noviazgo les parece más largo aquí. Otros piensan 
que las relaciones y el compromiso entre los cónyuges son más vinculantes: «Allí [Polonia] las parejas pasan más tiempo juntos; aquí el hombre se va a trabajar y la mujer queda en casa o se va a trabajar; todo empieza mucho más tarde y después del trabajo el hombre se va al bar a hablar con amigos, parece que sólo va a casa a cambiarse de ropa y a dormir...». «Aquí se ve las personas solas, todos [cada uno] viven su vida». Tras esta reflexión está la sociabilidad semipública del bar típica del español.

También nos informaron de la existencia de parejas de hecho con hijos naturales que, después de cierto tiempo, formalizan su situación canónicamente.

Una de las mayores críticas de los polacos en España respecto de las relaciones intersexuales es el machismo del español. Los celos y el control de la conducta de la mujer les parecen reprobables: «Los polacos no preguntamos a la mujer qué hace o dónde va». Otro informante polaco nos decía que, mientras su mujer estuvo en Canadá, «yo estuve con niñas, de cocinero, abuela, tío, ama de casa, todo». Una de nuestras entrevistadas, con diez años de residencia en España, se quejaba de que su marido antes compartía todas las tareas domésticas: «Ahora como trabaja tanto... pero es que se está pareciendo a los [maridos] españoles». Puede ser que estas críticas al machismo español se deban en parte al tipo de autóctonos con los que interactúan en el medio laboral, a menudo de escasa formación. Si bien se muestran tradicionales en otros aspectos, otorgan a la mujer un importante protagonismo, fruto también de más de cuatro décadas de ideología socialista con especial énfasis en la igualdad de derechos entre los sexos y en la incorporación masiva de la mujer al sector productivo.

En la época en que nos encontramos ya se encuentran familias constituidas en España. Por una parte, algunos de aquellos jóvenes que primero emigraron se han casado entre sí, formando sus familias en España, ya con uno o dos hijos. Por otro lado, se ha producido la reunificación familiar de otros que pudieron haber dejado mujer/marido e hijos en Polonia.

Comienza a haber matrimonios mixtos, si bien todavía es fuerte la relación endogámica. Afinidad religiosa, cultura de consumo y ocio occidentales son factores que, si no propician, al menos no dificultan la relación entre españoles/as y polacos/as. Se han podido conocer, sobre todo, en lugares de ocio: discotecas, pubs.

De entre todos los inmigrantes del este y centro de Europa, la comunidad polaca es la que más casos de segunda generación ofrece, tanto por su profundidad temporal como por los procesos de reunificación familiar en relación a una situación social y laboral cada vez más estable. La edad más alta de la segunda generación se encuentra en torno a la preadolescencia, entre 12 y 14 años, siendo más frecuente que los niños nacidos en España tengan poca edad. 
Los hijos se escolarizan en la red pública, estando el grueso matriculado en primaria, seguido por secundaria e infantil (Ministerio de Trabajo y Asuntos Sociales, 2001; datos del curso 1997-1998). Van a clases de lengua, historia y geografía polacas los sábados, en los distintos centros escolares que les ofrecen sus instalaciones para tal fin. Algunas parroquias y la Embajada también organizan alfabetización y actividades culturales para este fin. En los matrimonios mixtos, tanto si es el padre como la madre de origen polaco, parece haber un gran interés en que los hijos se eduquen también en esta lengua.

Nos cuentan que los niños tienen pocas oportunidades de hablar polaco a excepción de estos días y ocasiones, pues el contacto con los padres está mediatizado por sus prolongadas jornadas laborales, a pesar de que en casa se mantiene el polaco como lengua familiar. Reuniones con compatriotas en relación a fiestas, celebraciones, o el mes de vacaciones que los niños puedan pasar en Polonia con sus familias de origen, reavivan de inmediato la competencia de estos niños en la lengua de sus padres.

Los hijos nacidos en España conservan la nacionalidad de los padres, algo a lo que éstos no están dispuestos a renunciar, dados los vínculos y sentimientos patrióticos que caracterizan a esta diáspora. No hay convenio de nacionalidad entre Polonia y España. Nos cuentan casos de niños que se preguntan sobre su nacionalidad, a pesar de haber nacido ya en España, y las desventajas que puedan tener a la hora de participar en campeonatos escolares interprovinciales donde se exige la nacionalidad española.

En su opinión, los valores familiares no se mantienen en la sociedad española: «Los chicos contestan a su padres, dicen palabrotas. Eso no se puede permitir», comparaba un informante polaco. «Es que en España se nota mucho menos respeto de hijos a padres. Y menos disciplina, menos obedientes los hijos», dice otra. "Aquí es distinto, yo tengo veintitrés años y la gente de mi edad están siempre en la discoteca, salen, gastan, no es lo mismo que allí, [se] tiene mujer e hija y [se] busca trabajo». A los niños españoles se les da demasiada libertad, según la opinión de muchos. Una ética del esfuerzo y el trabajo acompaña esta ideología de las relaciones intergeneracionales: «Tienen que estudiar para poder salir y jugar, tienes que hacer algo antes que ir a divertirse[te]».

\section{III.2. Religiosidad y culto}

La religiosidad católica polaca se continúa en el ámbito migratorio. De esto da cuenta la constitución de grupos de feligreses en torno a determinadas parroquias que pueden contar incluso con sacerdotes polacos que ofician misa en esta lengua. La Capellanía polaca en Madrid es un ejemplo. 
Los ritos de paso (bautismo, comunión, matrimonio, muerte) se siguen sancionando por la Iglesia, tal como hubiera ocurrido en el lugar de origen, si bien con las modificaciones obvias en función del nuevo contexto migratorio. El calendario festivo cristiano también es observado: Navidad, Pascua, santoral. Los más leales a la tradición, principalmente algunas mujeres, siguen observando las prescripciones alimenticias de la Cuaresma, absteniéndose de carne y sus derivados en las fechas precisas, tal como se hacía en España no hace mucho tiempo. Durante esta época también es común bendecir alimentos en la iglesia para su posterior consumo en casa.

La religión católica sigue siendo parte de la constitución de la identidad polaca en la diáspora y referencia básica para su mantenimiento. La Iglesia católica ha encarnado el espíritu nacional de Polonia desde hace tiempo, constituyéndose en un poderoso aglutinante político y social, la única institución con una continuidad en la tradición nacional (Stierna, 1995). El orgullo de tener un Papa polaco es algo más que una simpatía por coincidencia geográfica, lingüística o cultural. Y es algo que manifiestan reiteradamente nuestros informantes. Como comentaremos más adelante, este catolicismo y la conservación de la práctica les han otorgado cierto lugar privilegiado en el imaginario étnico de los españoles.

No tenemos datos suficientes para conocer en qué medida esta comunidad inmigrante está influenciándose de posibles corrientes laicas que progresivamente van penetrando en el país de origen, tal como hemos podido comprobar in situ. La constitución del nuevo Estado polaco, después de la caída del Muro, sin grandes enemigos externos, con una población expuesta sin riesgos a influencias occidentales laicas, parece estar colocando en una encrucijada a la Iglesia polaca y sus relaciones con éste y con la sociedad civil. No sabemos cómo puede estar esto afectando a la diáspora y a su identidad construida en torno a los valores y prácticas religiosos católicos. Sí que hemos observado cierta relajación moral respecto de las relaciones prematrimoniales y el uso de anticonceptivos, por ejemplo. El aborto sigue siendo reprobable, por lo menos en la generalización de su aplicación: «Siempre hay que intentar antes otras cosas». Quizás esto explique en parte el nacimiento de algunos hijos fuera del matrimonio, como hemos comentado, siendo que su situación se regulariza a posteriori.

\section{III.3. Sociabilidad y ocio. Rutinas cotidianas}

La sociabilidad se concentra en torno al propio grupo, constituido por familiares o amigos, pero siempre compatriotas. La sociabilidad familiar y amical representa el escenario básico en donde se producen las prácticas principales del mantenimiento de la identidad. 
El poco tiempo libre que deja el trabajo se ocupa en descansar, comprar provisiones o visitar o celebrar en casa onomásticas o reuniones que se prolongan hasta bien entrada la noche, en una práctica que los polacos consideran muy propia, la de celebrar en casa y no en bares o restaurantes. La televisión es un recurso de distracción muy socorrido. Algunas de las comunidades de residencia de polacos con las que contactamos solían pasar la velada después de cenar pendientes de los concursos y películas de la televisión, decidiendo entre todos el programa de cada noche. La observancia del calendario religioso y sus rituales suele ser otro momento de encuentro, que, en general, implica muchas veces comensalía y degustación de platos y productos típicos del país que alguien haya podido preparar. Acudir al oficio dominical es un momento para la amistad, la compartición de información, el intercambio de medios de comunicación del país de origen, favores, datos relevantes, etc. Discotecas, pubs, bares, son algunos lugares de ocio frecuentados por los/las solteros/as, donde pueden relacionarse con otros compatriotas o españoles. Han podido visitar algunas ciudades turísticas de los alrededores gracias a la organización de excursiones por parte de los centros de acogida.

Una vida de ahorro y esfuerzo no permite dedicar grandes estipendios a las vacaciones. Éstas suelen pasarse en Polonia, a donde se llevan productos comprados en España para la familia o la casa que allí quedó. Una sólida y permanente infraestructura de transporte ayuda a la realización de estos viajes, o bien se va en grupo en coche alquilado o propio. Para aquellos con una situación laboral y administrativa irregular, o que acaban de llegar, vacacionar no entra dentro de los planes inmediatos, pues exige una situación económica y personal más normalizada: «Si nos vamos no sabemos si podemos volver a entrar», nos contaba un polaco recién llegado.

Los polacos suelen tener en general un buen dominio de su entorno, sobre todo referido a las rutas e itinerarios que han de transitar cotidianamente para ir y volver del trabajo. El metro, los autobuses, son utilizados y bien conocidos, representándose el mapa de la ciudad a menudo a partir de puntos e hitos concretos de los caminos que recorren (líneas y paradas de metro, cruce de calles, etc.). Las distancias son largas desde los barrios o localidades periféricos, sobre todo para las empleadas domésticas, y más si tienen varias casas que atender, tiempo que aprovechan para dormitar o ir estudiando o mirando el diccionario. Las jornadas de trabajo suelen ser largas, más que en Polonia; levantándose muy temprano, volviendo tarde, con menos tiempo para estar con la familia, aquellos que la tienen (Stierna, 1995). Los que trabajan en la construcción y llevan cierto tiempo establecidos pueden disponer de un automóvil o furgoneta, conveniente para sus traslados y los de otros compatriotas a las obras de distintos puntos de la provincia, y también para llevar materiales y herramientas. 


\section{III.4. Cultura doméstica, consumo, estilos de vida}

A los polacos les gusta la comida española, sobre todo, como a la mayoría de los extranjeros, la paella. Verduras y frutas que no disponen en su país son altamente apreciadas. Uno de nuestros informantes no cifraba en los ingredientes la diferencia entre la gastronomía polaca y la española, sino más bien en la forma de preparar los platos: platos preparados a base de carne picada o empanada, masas vegetales y arroz, gelatinas de carne o pollo. No hay que olvidar que la gastronomía y la comensalía son prácticas de generación de cultura «autóctona» por medio de la re-territorialización de los espacios en donde estas prácticas se producen (Ramírez Goicoechea, 1991). La actualización de la memoria personal y colectiva da continuidad cultural a la existencia por medio de estas actividades de reapropiación material y simbólica.

Tienen una cultura de consumo común a cualquier occidental europeo. Televisión y vídeo son dos aparatos que compran en cuanto pueden. El vídeo les permite establecer toda una serie de intercambios de cintas entre unos y otros. Películas, programas informativos, de variedades y espectáculos, concursos, fútbol, son los espacios de más audiencia. Cuando vuelven a su país suelen llevarse pequeños electrodomésticos (batidoras, secadores, tostadores, etc.) y otros enseres.

Una imaginería de progreso económico basado en fantasías como la lotería, moda, consumo de bienes o vacaciones en lugares turísticos de sol como las Canarias son algunas de las metas deseadas por algunos inmigrantes más jóvenes, no diferenciándose en eso ni en otras cosas de las ambiciones de consumo y calidad de vida de cualquier europeo.

Las revistas de moda, de variedades, de estilo, son algunos de los productos impresos que consumen, sobre todo algunas jóvenes. Ropa, zapatos y cosméticos son otros bienes muy apreciados. Las mujeres polacas en general, y sobre todo si son solteras y jóvenes, como cualquier española, dedican bastante atención a su arreglo y aspecto personal. Como nos decía un mediador social de un pueblo de la sierra de Madrid: «Las polacas van todas muy bien vestidas». Esto está en consonancia con su cultura de consumo occidental referente a ropa, cosméticos, moda en general. Domingos y festivos, bodas, fiestas y reuniones sociales son buenas ocasiones para esmerarse y acicalarse. Los hombres, sobre todo jóvenes, no se distinguen mucho de cualquier español de clase media: camisa, jersey, vaqueros, deportivas o zapatos.

La disponibilidad de un automóvil es otro objeto al que dedicar recursos y ahorros. Dispuestos a realizar los arreglos necesarios sin acudir al taller ni a profesionales, la compra suele ser de un coche de segunda mano, que les permitirá ahorrar en tiempo y dinero en sus trayectos, emplearlo para el trabajo y compartirlo para las vacaciones a Polonia. 
El nivel de gasto y de compra depende mucho del momento de la biografía migratoria de los sujetos, del grado de estabilidad de su asentamiento en el país, de sus objetivos personales de ahorro o envío de dinero a Polonia, etc. Hay una gran diferencia entre aquellos inmigrantes jóvenes, chicos y chicas sin cargas familiares en Polonia, excepto llevar o mandar algo de dinero a sus padres en vacaciones, que iniciaron el camino de la emigración como primer o segundo empleo, y entre aquellos de las primeras oleadas que vinieron al país generalmente solos, dejando cónyuge e hijos en Polonia. Las remesas que éstos envían suponen una entrada importante de divisas para el país y una fuerte ayuda económica.

La estabilidad laboral y residencial en España reorienta el gasto hacia la comodidad y bienestar de su estancia en el país: «Gasto todo ahora que tengo vida arreglada. Hemos empezado una vida normal. Compré la tele, cosas para la casa...». Parte del dinero también se va en mejorar sus condiciones residenciales: de compartir casa con cuatro, cinco o seis compatriotas, pasan a compartir con dos o tres, incrementándose su calidad de vida e intimidad personal.

\section{LAS RELACIONES ÉTNICAS}

\section{IV.1. Origen étnico}

A pesar de la presencia de alemanes, lituanos y ucranianos en Polonia, fruto de los vaivenes históricos y políticos, la mayoría de polacos en España no exhiben grandes diferencias étnicas entre sí, ni tampoco religiosas, siendo la inmensa mayoría católicos romanos. Comunidades polacas hay en Bielorusia, Lituania, Letonia (Öberg y Boubnova, 1993; Horak, 1985), resultado de los avatares históricos y la movilidad de las fronteras. Después de la Segunda Guerra Mundial, las fronteras de Polonia se desplazaron hacia el Oeste, quedando la Silesia incorporada al territorio polaco, y de ahí un grupo de origen alemán. Por otro lado, Polonia perdió sus territorios en Ucrania, quedando también allí una fuerte comunidad de origen polaco, que también fue diseminada en tiempos de Stalin por el resto de Repúblicas de la antigua URSS. A pesar de la existencia de algún grupo étnicamente devaluado (Pine, 1996), Polonia se convirtió en un país «étnicamente» homogéneo a partir de la Segunda Guerra Mundial (Farmer, 1985) y las atrocidades de la «limpieza étnica» nazi contra la comunidad judía polaca.

\section{IV.2. España y los españoles vistos por los europeos del Este}

En general, estos inmigrantes están contentos de estar en España. Aquellos que han pasado primero por Francia o Alemania destacan las diferencias. Una es el clima, aspecto 
que no ha de minusvalorarse para personas que tienen que salir, entrar, trabajar a menudo al aire libre, etc. Si para emigrantes de lugares cálidos España es una sorpresa por sus inviernos, para los polacos la suavidad del clima comparada con la de sus lugares de origen les hace más llevadera su vida cotidiana y de ocio. Lo que no impide que, para algunos, España sea «un desierto», con «cuatro hierbas secas», como nos decía una señora polaca de cierta edad.

También encuentran a los españoles más afectivos y «divertidos» que incluso ellos mismos: «nosotros tristes, más fríos». "Aquí la gente en fiestas canta, baila, bebe, come». Pero, por otra parte, los encuentran a veces demasiado espontáneos, rayando en la mala educación, sobre todo en términos de cortesía, etiqueta e incluso «maneras de mesa».

La falta de prejuicios étnicos de los españoles hacia estos inmigrantes europeos (a los que a veces les cuesta situar geográficamente), con quienes no les desune una historia de agravios comparativos y a quienes encuentran menos lejanos culturalmente que a otros (Ramírez Goicoechea, 1996b) (cf. infra), hace que perciban a los españoles «menos racistas» que a los alemanes, por ejemplo. La solidaridad de los españoles es algo que valoran y aprecian, así como la facilidad de contacto y comunicación: «En España puedes hacer amistad. En Alemania no quieren hablar contigo, aquí te hablan todo, en otros países no es así».

Si el carácter extrovertido de los españoles es algo a valorar, por otra parte, el llamativo exceso de bares y horas dedicadas al ocio les hace supravalorarse en cuanto a su cultura del trabajo y disciplina. Los que están acostumbrados a la «eficiencia» administrativa alemana, llaman la atención sobre la escasa cultura de servicio al usuario que ha sido una de las característica endémicas de la administración española. También la deficiente cobertura social en algunos aspectos.

Anteriormente ya hemos comentado algunas de las opiniones de los polacos sobre los españoles en lo que se refiere a las relaciones entre los sexos, el papel de la mujer y las relaciones intergeneracionales (cf. supra). Decíamos que esto podría deberse al tipo de interlocutores españoles con los que se relacionan, sobre todo los hombres, en el mundo de la construcción, donde la formación del trabajador autóctono no siempre es muy elevada. Eso mismo pasa cuando se trata del bagaje cultural general: los españoles son percibidos como incultos y malos ciudadanos que descuidan la limpieza de su entorno, aunque con el transcurrir del tiempo y la diversificación de los contactos esta opinión suele matizarse. Están orgullosos de su amplia formación cultural: «Nivel de cultura [de los españoles en] comparación con polacos, muy bajo», nos contaban. «Por ejemplo, no saben dónde está Polonia, sólo saben dónde está Alemania, Francia, nada más». Las cifras oficiales de 
estudiantes que terminan secundaria son más elevadas en el caso polaco que el español y así se confirma en el discurso de algunos inmigrantes: «Me parece bajo el nivel de estudios aquí en colegios públicos, ... en Polonia es obligatorio ir a colegio hasta dieciocho años, ocho cursos de colegio y tres o cinco de secundaria»; «Los chicos españoles no saben nada, no aprenden nada. Un chico en Polonia sabe muchas más cosas en la escuela»; «En Polonia los niños de trece y quince años saben toda la geografía y dónde están todos los países del mundo y saben de todos los escritores del mundo, ... y aquí los que conocemos saben leer y escribir y nada más». Éstas son opiniones sobre el sistema educativo polaco de los setenta y ochenta, sin que tengamos información sobre las posibles variaciones sufridas en la calidad de la enseñanza en el país a partir de la crisis económica de la última época socialista y durante la transición política.

Ante el posible rechazo de los españoles, además de su mayor nivel cultural y formación, los polacos arguyen su «incontaminación» de cualquier contacto con culturas que desde una supremacía «europea» consideran como «inferiores»: la cultura árabe. Algo que, dicen, no pueden decir los españoles, después de tantos siglos de presencia y mezcla con los árabes en España. Además, su actitud respecto de otros migrantes se corresponde en gran medida con los estereotipos y prejuicios que los españoles construyen sobre otros grupos más estigmatizados: también los polacos rechazan a los magrebíes y a los subsaharianos. Su versatilidad es argüida como otra diferencia, con consecuencias para su integración positiva en España: «si comparas con otros como marroquíes, entonces, nosotros adaptarnos mejor [que ellos]».

\section{IV.3. Actitudes de los españoles hacia los polacos}

Creemos poder decir con cierta seguridad que los europeos del Este en general, y los polacos en particular, son uno de los grupos inmigrantes mejor aceptados en España. Casi todas las encuestas sobre xenofobia, a pesar de algunas dudas razonables sobre los criterios de clasificación, confirman este extremo, que parece mantenerse en distintas consultas a lo largo del tiempo (Díez Nicolás, 1999; CIS, 1995). Los inmigrantes del Este europeo no constituyen en el imaginario español sobre la inmigración un problema (Ramírez Goicoechea, 1996b). Son otros colectivos, especialmente el marroquí y el gitano, quienes encarnan la alteridad étnica máxima en el mapa clasificatorio de los españoles, sobre los que se ha construido la identidad étnica española (Stallaert, 1996).

Ellos mismos se reconocen mejor tratados por los españoles en comparación con otros grupos y eso les da cierta autoconfianza en las posibilidades de empleo y vida en España: «A los polacos, policía más tolerancia»; «Aquí nunca nos han rechazado». 
Los ejes principales sobre los que se organiza esta actitud favorable a los polacos y otros europeos son los siguientes:

Entre los empresarios españoles se ha formado el mito del «buen trabajador» polaco. Muchos de los anuncios demandando mano de obra especifican la nacionalidad deseada. «Los polacos no tienen problema para encontrar trabajo»; «Españoles piensan que son buenos trabajadores, y prefieren: dicen [en anuncios] quiere albañil polaco, quiere chica [para limpiar] polaca».

Lo interesante del caso es la relevancia del sistema clasificatorio, del imaginario social, a la hora de entender los procesos de estructuración y segmentación laboral, por medio de las prácticas de contratación y promoción en el empleo. A muchos se les reconoce la cualificación de «oficial» cuando a lo mejor en sus países no lo eran o ni siquiera habían trabajado como tales (Colectivo IOE, 1998). Aunque esto no quiere decir que les sea fácil recuperar una concordancia entre formación y empleo.

Los rasgos fenotípicos también cuentan, con un alto poder discriminante (en el sentido clasificatorio) en la experiencia cotidiana. La complexión y rasgos eslavos de algunos -elevada estatura, pelo rubio, ojos claros, etc.- - de muchos polacos/as, representa la antítesis de los rasgos atribuidos a otros inmigrantes, acercándolos más a una caracterización nórdica siempre apreciada en España. Una informante polaca aseguraba que cuando ella llegó, hace diez años, la gente no sabía dónde estaba Polonia y les confundían a menudo con anglosajones, por su aspecto físico y su habla «extraña»: «A los polacos se les nota que son del Norte».

Estéticas e indumentarias pueden funcionar también en el mismo sentido. Aquella voluntad por seguir la moda por parte de muchas chicas jóvenes polacas que comentábamos anteriormente, una indumentaria tipo indistinguible de la de un/a español/a de clase media, sobre todo en aquellos de procedencia urbana, favorecen la «invisibilidad» del colectivo y su proximidad estética y visual con los/las españoles/as, aunque sus compatriotas dispongan de sutiles mecanismos de reconocimiento de sus iguales a este respecto.

Aspectos de proximidad cultural son aducidos tanto por estos europeos como por españoles como claves interpretativas de esta benevolencia y proximidad. «Nosotros no tan diferentes, no tenemos costumbres tan diferentes [de las de los españoles]». En las culturas domésticas también se aprecia cierta proximidad, así como en la organización del espacio y los tipos de consumo, por lo menos con respecto a otros grupos de inmigrantes percibidos como más distantes culturalmente. 
A pesar de que algunos no sean creyentes, la compartición de la religión católica es un elemento que acerca a estos inmigrantes comparativamente respecto de otras confesiones y otros practicantes. Ellos mismos son conscientes y manipulan esta diferencia a su favor. El nivel de práctica y creencias de algunos inspiran respeto en una población como la española que se ha ido secularizando progresivamente.

La compartición de centros de culto de la Iglesia española para la celebración de los oficios, como pueda ser en el caso de las parroquias de Ntra. Sra. de la Paz o de Nuestra Señora en la calle Félix Boix, ambas de Madrid, propicia una proximidad, si quiera perceptual y clasificatoria, de estos grupos con la feligresía española. La celebración de bodas, bautizos, funerales, Navidades, Pascua, etc., son otras prácticas que son percibidas como culturalmente compartidas entre receptores y recibidos.

Una de las explicaciones aducidas para la benevolencia de los españoles hacia los polacos consiste en la normalización del colectivo y la progresiva desaparición de conflictos relacionados con el consumo del alcohol: «Sólo al principio [nos han rechazado], porque mucha gente en pisos y como fiestas en Polonia siempre celebrar en casa, porque no había bares y más barato, pues aquí también. Y entonces mucho ruido y beber, mucho escándalo, y entonces vecinos protestan. Ahora ya no, desaparecido. Ahora beber ya no es fin de semana a tope, sino más normal, más como españoles».

\section{IV.4. Sensación subjetiva de su situación/condición. Discursos de la identidad}

Cómo se sienten estos inmigrantes en España tiene mucho que ver con lo tratado en los epígrafes anteriores. Aun conscientes de no ahondar en las múltiples dimensiones de su subjetividad, como migrantes desplazados de sus países de origen, de sus familias, sus tradiciones, de sus lugares conocidos y compartidos, queremos hacer mención de algunos aspectos interesantes que los particularizan en comparación con otros y que les permiten una estrategia de autopercepción y reivindicación de un lugar concreto en el panorama migratorio y étnico español (cf. Ramírez Goicoechea, 2002a).

La voluntad de desidentificarse como inmigrante, de restituir su estatus originario, de reubicarse objetivamente en la estructura social, de redefinir una identidad social devaluada por una «descualificación» necesaria para acceder y trabajar en el país de acogida, resume lo observado para una gran parte de esta población. Su identidad étnica no es el «problema», como veremos más abajo.

Existe una tensión entre la ubicación objetiva en la estructura social, por una parte, y, por otra, la sensación subjetiva sobre su condición y situación, marcada sobre todo por un in- 
negable «desclasamiento». Como nos decía una chica polaca, «no es agradable salir de una oficina para lavar camisas o bragas de alguien que no conoces».

Para éstos, la restitución de una identidad social y moral degradada por las necesidades materiales asociadas a la emigración pasa por las posibilidades de una promoción laboral en el lugar de destino. Perciben su situación como transitoria, modificable en función de la posibilidad de alcanzar un puesto de trabajo, un lugar social, que les devuelva un prestigio y dignidad previos basados en su formación, estilo de vida, etc. Pero esta posibilidad de autorrepresentación depende también de una confirmación en la estructura social en términos no sólo de remuneración, sino del estatus que un tipo de empleo incorpora frente a otros. Los intentos de alcanzar puestos o realizar actividades para los que están cualificados han de entenderse también desde esta óptica y no sólo desde una estrategia de incremento en la capacidad adquisitiva.

Asimismo, hemos detectado otros vectores interesantes en estas redefiniciones clasificatorias. La denominación de «inmigrante» se sustituye por la de «extranjero», calificativo que se aplica a otros colectivos europeos en España y que apunta a connotaciones más neutras, más cosmopolitas y menos devaluadas. Según lo que decíamos en el apartado anterior, el sistema clasificatorio que los centros de producción de sentido autóctonos - sujetos, grupos, medios de comunicación, poderes públicos y administrativos, instituciones, etc.- manejan en torno a este grupo inmigrante propicia una consideración diferente del mismo comparado con otros en cuanto a su «problematicidad» y estigma. Su estatus europeo les rescata definitivamente de la connotación de «tercermundista» que se adjudica a otros inmigrantes, orientación que el propio colectivo defiende y comparte cuando se autocompara con otros trabajadores extranjeros.

Los polacos mantienen una fuerte identidad étnica y nacional. Se sienten «muy» polacos, como nos decía un informante, y «siempre lo seremos». Esta identidad se mantiene independientemente del tiempo de permanencia en España y se vincula tanto al país de origen como a la diáspora. Es improbable el cambio de nacionalidad, máxime cuando la polaca pertenecerá a la UE en un futuro próximo. De hecho, el número de nacionalizaciones, con ser pocas, descendió de 1998 a 1999 en un 30\% (Ministerio de Trabajo y Asuntos Sociales, 2001).

Como hemos ido explicando a lo largo de los distintos epígrafes, la identidad se mantiene en torno a prácticas culturales como el idioma, la religión y el culto católico, la comensalía y la sociabilidad con los compatriotas, los intercambios de productos y noticias del país de origen, la educación de los hijos en la lengua y cultura polacas a través de las escuelas de fin de semana y las visitas de familiares, las cartas y llamadas a los parientes, la celebra- 
ción de las fiestas nacionales privada u organizadamente. En el punto l.3 también nos referimos a las formas de autoorganización del colectivo en el ámbito institucional y asociativo. Como hemos mencionado en otro lugar (Ramírez Goicoechea, 1997), podemos vaticinar un futuro próximo en el que hablaremos de la comunidad étnica polaca, y no ya de inmigrantes polacos.

\section{EPÍLOGO. EL FUTURO DE LA COMUNIDAD POLACA EN ESPAÑA}

No es fácil predecir el futuro ni es nuestro cometido aquí. Pero dada la relativa estabilidad del colectivo polaco en España, y según lo que acabamos de apuntar sobre la constitución de la comunidad étnica, es pensable la consolidación de un proceso de normalización que se ha ido dando progresivamente a lo largo de la década de los noventa. En principio es de esperar que los flujos continúen, sobre todo para aquellos provenientes de áreas rurales deprimidas («Yo creo que muchos jóvenes como nosotros van a seguir viniendo, allí no hay nada que hacer. Tampoco pierden mucho si vienen») y en relación a posibles convenios de colaboración entre ambos países. El retorno estará marcado por el grado de integración cultural y biográfico de la segunda generación, así como por la evolución de los datos económicos y de empleo de su país de origen, Polonia.

Pero habrá una diferencia capital entre polacos y otros centroeuropeos, por un lado, y respecto de otros inmigrantes transcontinentales, por otro. Pronto sus nacionales serán ciudadanos de pleno derecho de la UE, constituyéndose Polonia en frontera exterior de la misma, por donde ya pasan una gran cantidad de transeúntes hacia Europa occidental. Su situación administrativa cambiará radicalmente, liberándose de las constricciones de políticas migratorias, permisos de trabajo, residencia, etc. Accederán de pleno derecho a todos los beneficios del Estado de bienestar, en igualdad de condiciones con cualquier español. Los polacos, aunque teniendo que resolver cuestiones de vida como cualquiera, dejarán entonces de ser «Inmigrantes en España». 


\section{BIBLIOGRAFÍA*}

AGUILERA, M. J.; GONZÁLEZ YANCI, M. P., y RODRÍGUEZ, V. (1994): Inmigrantes polacos en España. Informe, Madrid: Fundación Largo Caballero/Dir. Gral. de Migraciones, Ministerio de Asuntos Sociales. A.

APPADURAI, A. (2000): Modernity at Large. Cultural dimensions of Globalization, Minneapolis: University of Minnesota Press.

ARDITTIS, S. (1994): «East-West Migration. An Overview of trends and issues», en S. Ardittis (ed.), The Politics of East-West Migration, Chicago: St. Martin's Press. A.

ARNAL SARASA, M. D. (1998a): Inmigrantes polacos en España, Tesis Doctoral, Universidad Complutense, Madrid. C.

- (1998b): «La religiosidad polaca en la inmigración: un análisis cualitativo», Ofrim, Suplementos, junio, pp. 117131. C.

- (1999): «La otra migración: vivencias de los inmigrantes polacos en España», Revista del Ministerio de Trabajo y Asuntos Sociales, 20, pp. 31-68. C.

BLUMI, I. (1998): «The Commodification of Otherness and the Ethnic Unit in the Balkans: How to think About Albanians", East European Politics and Societies, 12, 3, pp. 527-569. A/C.

BOBINSKA, C., y GALOS, A. (1980): «Poland: Land of Mass Emigration (XIXth \& XXth Centuries)», en Commission Internationale d'Histoire des Mouvementes Sociaux et des Structures Sociales, Les migrations internationales de la fin du XVIIlème siècle à nos jours, París: CNRS, pp. 467-502. A.

BORNEMAN, J. (1992): Belonging in the Two Berlins, Cambridge: CUP. A/C.

CHESNAIS, J. C. (1992): «Europa. Escenario de la Inmigración del Este», en Itinera, Madrid: Fundación Torras Domenech, pp. 402-435. A.

CIRES (1992): La realidad social en España. 1990-1991, Bilbao: BBV, BBK y Caja Madrid. A.

CIS (1995): Discursos de los españoles sobre los extranjeros. Paradojas de la alteridad, Opiniones y Actitudes, 8 , Madrid. A.

COLECTIVO IOE (1997, 1998): Inmigración y Trabajo. Trabajadores inmigrantes en el sector de la construcción. Polacos y marroquíes en Madrid y Barcelona, Madrid: Ministerio de Trabajo y Asuntos Sociales, Observatorio Permanente de la Inmigración. A/C.

CUTHBERTSON, I. M., y LEIBOWITZ, J. (eds.) (1993): Minorities: The new Europe's old issue, Prague-BudapestWarsaw-New York-Atlanta: Institute for East-West Studies. A.

DÍEZ NICOLÁS, J. (1999): Los españoles y la inmigración, Madrid: IMSERSO, Ministerio de Trabajo y Asuntos Sociales. A.

* La bibliografía sobre la comunidad polaca es diversa y heterogénea. Referencias a este colectivo aparecen, a veces, incluidas en estudios más generales sobre la inmigración procedente de los países ex socialistas de Europa. A los efectos de este trabajo, he dividido las referencias en tres tipos básicos: A) bibliografía general sobre la emigración de los países del Este de Europa, orientada mayoritariamente hacia aspectos económicos y sociodemográficos, contribuciones de tipo histórico y teórico sobre migraciones, ciudadanía y exclusión social; B) bibliografía desde las propias comunidades y organizaciones polacas en España, con informaciones desde la experiencia personal y la evolución del asentamiento del colectivo; y C) trabajos de investigación que incorporan análisis cuantitativos y cualitativos de esta migración, incluyendo aspectos culturales y étnicos; ésta es la clase a la que pertenecería este artículo. Junto a cada reseña se consigna el modelo al que más se ajusta su contenido y orientación teórico-metodológica. 
FARMER, K. C. (1985): «National Minorities in Polland, 1919-1980», en S. Horak (ed.), Eastern European National Minorities. 1919-1980. A Handbook, Littleton, Colorado: Libraries Unlimited, Inc., pp. 35-107. A.

FRIEDMAN, J. (1994): Cultural Identity \& Global Process, London: SAGE.

FODOR, E. (1997): «Gender in Transition: Unemployement in Hungary, Poland, and Slovakia», East European Politics and Societies, 11, 3, pp. 470-500. A.

GHOSH, B. (1994): “The future of East-West Migration», en S. Ardittis (ed.), The Politics of East-West Migration, Chicago: St. Martin's Press. A.

GLENNY, M. (1992): The Fall of Yugoslavia: the Third Balkan War, Harmondsworth: Penguin.

GORA, M. (1991): «Tratamiento de choque para el mercado laboral polaco», Revista Internacional del Trabajo, vol. 110, 3, pp. 311-332. A.

GORZELAK, G. (1992): «Regionalismo y regionalización en Polonia», Estudios Territoriales, 40, pp. 47-62. A.

GRECIC, V. (1991): «East-West migration and its possible influence on South-North Migration», en 9th Conference of Migrations: "South-North Migrations», IOM, vol. XXIX, 2, June. A.

HAMMAR, Th. (1190): International Migration. Citizenship and Democracy, Avebury, Aldershot: Gower Publishing.

HANN, C. (1985): A village without Solidarity. Polish peasants in years of crisis, New Haven: Yale University Press. $\mathrm{A} / \mathrm{C}$

HANNERZ, U. (1996): Transnational Connections, London: Routledge.

HOLLIFIELD, J. (1992): Immigrants, markets and states: The political economy of postwar Europe, Cambridge, MA: Harvard University Press. A.

HORAK, S. (1985): «Easter European National Minorities, 1919-1980», en S. Horak (ed.), Eastern European National Minorities. 1919-1980. A Handbook, Littleton, Colorado: Libraries Unlimited, Inc., pp. 1-34. A.

KEITH, S. (1989): The formation of the Polish community in Great Britain. 1939-1950, London: School of Slavonic and Eastern European Studies/University of London. A.

KEMPER, F. J. (1993): «New trends in mass migration in Germany», en R. King (ed.), Mass Migration in Europe. The legacy and the future, London: Bellhaven Press, pp. 257-274. A.

KING, R. (1993): «European international migration 1945-90: a statistical and geographical overview», en R. King (ed.), Mass Migration in Europe. The legacy and the future, London: Bellhaven Press, pp. 19-39. A.

INSTITUTO UNIVERSITARIO DE NUEVAS TECNOLOGÍAS (1995): Informe sobre la integración social de los inmigrantes extranjeros en España, Madrid: UAM. A.

LAYTON-HENRY, Z. (1990): “Citizenship or Denizanship for Migrant Workers?», en Z. Layton-Henry (ed.), The political rights of Migrant workers in Western Europe, London: SAGE, pp. 186-195. A.

LORA TAMAYO, G. (1999): Población extranjera en la Comunidad de Madrid. Perfil y distribución, Madrid: Delegación Diocesana de Migraciones. A.

LORCA, A.; ALONSO, M., y LOZANO, L. A. (1997): Inmigración en las fronteras de la Unión Europea, Madrid: Encuentro. A.

MAKOWSKI, B. (1967): History and Integration of Poles in Canada, Toronto. A. 
MEHAN, Ch. (1963): Polish Migration and Settlement in the USA, New York. A.

MINISTERIO DEL INTERIOR (2001): Datos Balance 2001, Madrid: Delegación del Gobierno para la Extranjería y la Inmigración. A.

MINISTERIO DE TRABAJO Y ASUNTOS SOCIALES (2000): Anuario de Migraciones 2000. A.

MOROKVASIC, M. (1991): «Roads to independence. Self-employed immigrants and minority women in five European countries», International Migration, 29, p. 3. A.

ÖBERG, S., y BOUBNOVA, H. (1993): «Ethnicity, nationality and migration potentials in Eastern Europe», en R. King (ed.), Mass Migration in Europe. The legacy and the future, London: Bellhaven Press, pp. 234-256. A.

OKOLSKI, M. (1991): Movimientos migratorios provenientes de los países de Europa central y oriental, Cuaderno 108, febrero, Madrid: Fundación Encuentro. A.

- (1994): «Vers une nouvelle politique des migrations en Pologne», en OCDE, Migration et Développement, París, pp. 69-76. A.

PINE, F. (1996): «Naming the House and naming the Land: Kinship and social groups in Highland Poland», J. Roy. Anthrop. Inst. (NS), 2, pp. 443-459. C.

PORTES, A., y BÓRÓCZ, J. (1992): «Inmigración contemporánea: perspectivas teóricas sobre sus determinantes y modos de acceso», Alfoz, 91-92, pp. 30-33. A.

RAMÍREZ GOICOECHEA, E. (1991): De Jóvenes y sus identidades. Socioantropología de la Etnicidad en Euskadi, Madrid: CIS/Siglo XXI.

— (1996a): Inmigrantes en España. Vidas y experiencias, Madrid: CIS/Siglo XXI. C.

— (1996b): «Inmigrantes Europeos: la distancia próxima», Arbor, CLIV, julio, pp. 65-89. C.

- (1997): «Investigación en inmigración. Actitudes y sugerencias», ponencia Congreso La Inmigración en España, Madrid: Instituto Universitario Ortega y Gasset/Fundació La Caixa. A.

- (2001): «Europeos del Este», Máster de Inmigración a Distancia, Unidad Didáctica, Universidad Pontificia de Comillas. A/C.

- (2003): «Sociosymbolic Aspects of Social Exclusion. Some clues for the study of migrant integration». En evaluación, 28 pp. C.

- (2003): «Spolecznosc imigrantów polskich w Hiszpanii», en J. Zamosky y E. González (comps.), España y Polonia: el encuentro entre dos países, Varsovia: Neriton/Academia de Ciencias de la Historia de Polonia. A.

RIST, R. C. (1979): «Guestworkers in Germany: public policies as the legitimation of marginality», Ethnic and Racial Studies, vol. 2, 4, pp. 401-415. A/C.

RODRÍGUEZ RODRÍGUEZ, V. (1995): «Los polacos en España: de refugiados a inmigrantes», Estudios Geográficos, LVI, 220, julio-septiembre, pp. 521-546. B.

SHEVTSOVA, L. (1992): «Post-Soviet Emigration Today and Tomorrow», International Migration Review, XXVI, 2 , pp. 241-257. A.

SOPEMI (1981): Polland 1980, Bruxelles: OCDE. A.

- (1995): Tendances des Migrations Internationales. Rapport Annuel 1994, Bruxelles: OCDE. A. 
STIERNA, J. (1995): «Una interpretación de la Cultura Polaca, desde una perspectiva migratoria», en Varios, Educación Plural y Solidaria, Año Internacional de la Tolerancia, Madrid: Ministerio de Educación y Ciencia, pp. 139-152. B.

STALLAERT, Ch. (1998): Etnogénesis y Etnicidad, Barcelona: Proyecto A de Ediciones. A.

SUGAR, P. F. (ed.) (1980): Ethnic Diversity and Conflict in Eastern Europe, Santa Bárbara: ABC-Clio. A.

THOMAS, W. I., y ZNANIECKI, F. (1958): 1918-1920. The Polish Peasant in Europe and America, 2 vols., New York: Dover. C.

THRÁNHARDT, D. (1992): «The political uses of xenophobia», en R. Layard, O. Blanchard, R. Dornbusch y P. Krugman, East-West Migration. The Alternative, Cambridge, Mass.: MIT. A.

TORTOSA, J. M. (1993): «La transición al mercado y empobrecimiento: aplicación al caso de Polonia», Sociología del Trabajo, 17, pp. 73-89. A.

WALICKI, A. (1997): «Intellectual Elites and the Vicissitudes of "Imagined Nation" in Poland», East European Politics and Societies, 11, 3, pp. 227-253. A.

WERBNER, P. (1999): «Global Pathways. Working class cosmopolitans and the creation of transnational ethnic worlds», Social Anthropology, 7, pp. 17-35. A.

ZUBRZYCKI, J. (1953): «Emigration from Poland in the Nineteenth and Twentieth Centuries», Population Studies, 1, 3. A.

- (1956): Polish Immigrants in Britain, The Hague.

\section{ABSTRACT}

The aim of this paper is to offer an overview of the Polish migration to Spain. Based on different ethnographic field works, I will try to show the singularity of this group compared to other migrants in Spain: their European origin, their best position in the ethnic scale of the Spanish population imagery, and, last but not least, the difference introduced by the forthcoming integration of Polland in the UE. Polish migrants are described through the analysis of their migratory culture and experience, administrative situation in Spain, social networks, sociodemographic profile, cultural practices and ethnic relationships. 